\title{
FORUM
}

\section{The Ethics of Using Large Tankers}

\author{
Captain J.F. Kemp
}

Commandant Oudet's paper 'The Black Flood' 1 is a masterly analysis of the circumstances surrounding the loss of the Torrey Canyon. We have come to expect contributions of this standard from Commandant Oudet, so much so that one wonders whether the sort of international tribunal which he advocates would be more effective in pointing to the lessons to be learned from casualties than Commandant Oudet's own work has been for many years past. In his discussion of the Torrey Canyon loss, Commandant Oudet raises the question of whether the size of tankers should be limited. This question has been voiced elsewhere with the implication that, economics apart, the trend towards larger and larger tankers is a bad thing. It deserves a more detailed study.

To simplify this study a hypothetical case is considered in which a company has to transport oil at a rate of 200,000 tons per week between two ports where the round voyage takes two weeks. In theory this could be done using one 400,000-ton tanker, two 200,000-ton tankers, ... sixteen 25,000-ton tankers, ...forty 10,000-ton tankers.... Economic considerations favour the use of large tankers provided there is sufficient water at the two terminals and enroute, but is this morally justified in view of the possibility of repetitions of the Torrey Canyon incident?

The annual loss of ships from collision, shipwreck, foundering, \&c. (but not including fire) is of the order of $1 / 3$ per cent of the ships at risk, i.e. one ship in 300 may be expected to be so lost every year. ${ }^{2}$ Assuming that the degree of risk is independent of ship size, the probability of losing a single 400,000-ton ship in a year's operation is $1 / 300$. The probability of losing ships from a larger fleet of smaller ships follows a binomial distribution. Thus the probability of losing one or more units during a year's operation from a fleet of sixteen 25 ,000ton ships is $I-(299 / 300)^{16}=0.05^{2}$. The probability of losing one ship from such a fleet in the course of a year and thus spilling exactly 25,000 tons of oil is slightly less than sixteen times the probability of losing a single 400,000-ton ship, but the small probability of losing more than one of the sixteen-unit fleet must also be taken into account. If a large quantity of oil is to be transported over an extended period of time, the likelihood is that the same quantity of oil will be spilt whether 25,000 -ton or 400,000 -ton ships are used.

Since the same quantity of oil is likely to be spilt over a period, the case against large tankers rests on the magnitude of the problem when it occurs. The question is whether a large number of relatively frequent small spillages spread over a wide area is preferable to a rare very large spillage. On a route such as the Persian Gulf to N. Europe, a spillage will cause trouble wherever it occurs and the rare very large spillage is likely to be cheaper to clear up and to cause less widespread pollution than say sixteen smaller spillages. On the other hand, a single vêry large spillage will affect a limited coastline and it is possible that the country or countries concerned may not have the necessary facilities for coping 
with the problem. It is important that international agreement should be reached on the mechanism for dealing with future spillages and on the means of financing the operations by insurance or otherwise.

So far it has been assumed that the probability of loss is the same for large ships as for small. There is a considerable weight of evidence 2 to show that the probability of losing a small ship is significantly greater than that of losing a large ship. Past experience with ships of over 100 tons gross suggests that the probability of losing a ship over $400 \mathrm{ft}$. in length due to collision, stranding or foundering is less than half that of losing a ship under $400 \mathrm{ft}$. in length. The greater casualty rate for small ships is no doubt to some extent due to the fact that many are engaged in coastwise trades where stranding and collision risks may be greater. Nevertheless, there is prima-facie statistical evidence that on a given route the casualty rate for large tankers may be expected to be less than for small ones and thus that the total quantity of oil spilt over a period will have an inverse relationship to the size of tanker employed.

Risk of collision on a particular route is a function of the number of ships employed on that route. If a single 400,000-ton tanker is the only craft commuting on a particular route, the risk of collision is zero. If more than one tanker is employed a risk exists and collisions have occurred between ferry craft operating such a shuttle service. Thus, if sixteen 25,000-ton craft are employed the collision risk is increased. This is clearly a further argument in favour of large tankers. The reduction in collision risk gained by using a smaller number of tankers will be marginal where the route is shared by a large volume of other traffic, but will be significant where the incidence of other traffic is small in relation to the number of tankers employed. Even a marginal reduction in collision risk is worth having.

In the above notes, economic considerations such as running costs, terminal costs, availability of alternative tonnage for charter should a unit become a casualty, \&c., have not been discussed. The object has been to examine the ethical case for or against large tankers should their use on a particular route be indicated by economic considerations. The following conclusions are drawn:

I. Assuming a casualty rate independent of ship size the quantity of oil likely to be spilt over a period of time will be the same whether large ships or small ships are employed.

2. Provided that agreement can be reached on the technical and financial arrangements for dealing with spillages, the occasional large spillage associated with the use of large tankers is likely to be less damaging overall than the more frequent spillages associated with the use of small tankers.

3. Statistical evidence and, in the case of collisions, analytical evidence, suggests that the casualty rate for large tankers is likely to be less than for small tankers. The quantity of oil spilt over a period if large tankers are used may thus be expected to be less than the quantity spilt if small tankers are employed.

\section{REFEREN CES}

1 Oudet, ${ }^{i}$ L. (1968). The black flood. This Journal, 21, $4^{1}$.

2 Manley, C. V. (1965). Merchant ship losses-a general review. Trans. R.I.N.A. 107, 539 . 